\title{
Approximation by generalized Stancu type integral operators involving Sheffer polynomials
}

\section{Mursaleen ${ }^{1}$, Shagufta RAHMAN ${ }^{2}$ and KHursheed J. AnsAri ${ }^{3}$}

\section{ABSTRACT.}

In this article, we give a generalization of integral operators which involves Sheffer polynomials introduced by Sucu and Büyükyazici. We obtain approximation properties of our operators with the help of the universal Korovkin's theorem and study convergence properties by using modulus of continuity, the second order modulus of smoothness and Peetre's $K$-functional. We have also established Voronovskaja type asymptotic formula. Furthermore, we study the convergence of these operators in weighted spaces of functions on the positive semi-axis and estimate the approximation by using weighted modulus of continuity.

Acknowledgement. The authors extend their appreciation to the Deanship of Scientific Research at King Khalid University for funding this work through research groups program under grant number R.G.P. 1/13/38.

\section{REFERENCES}

[1] Acar, T., Asymptotic Formulas for Generalized Szász-Mirakyan Operators, Appl. Math. Comput., 263 (2015), 223-239

[2] Acar, T. and Ulusoy, G., Approximation Properties of Generalized Szász-Durrmeyer Operators, Period. Math. Hungar., 72 (2016), No. 1, 64-75

[3] Acar, T., Quantitative q-Voronovskaya and q-Grüss-Voronovskaya-type results for q-Szász Operators, Georgian Math. J., 23 (2016), No. 4, 459-468

[4] Altomare, F. and Campiti, M., Korovkin Type Approximation Theory and its Applications, in: De Gruyter Studies in Mathematics, vol. 17, Walter de Gruyter, Berlin, New York, 1994

[5] Aral, A., A generalization of Szász-Mirakyan operators based on q integers, Math. Comput. Modelling, 47 (2008), No. (9-10), 1052-1062

[6] Atakut, Ç. and Büyükyazıcı, İ., Approximation by modified integral type Jakimovski-Leviatan operators, Filomat, 30 (2016), No. 1, 29-39

[7] Braha, N. L., Loku, V. and Srivastava, H. M., $\Lambda^{2}$-Weighted statistical convergence and Korovkin and Voronovskaya type theorems, Appl. Math. Comput., 266 (2015), 675-686

[8] Braha, N. L., Srivastava, H. M. and Mohiuddine, S. A., A Korovkin's type approximation theorem for periodic functions via the statistical summability of the generalized de la Vallã (C) Poussin mean, Appl. Math. Comput., 228 (2014), 162-169

[9] Ciupa, A., A class of integral Favard-Szász type operators, Studia. Univ. Babeş-Bolyai Math., 40 (1995), No. 1, 39-47

[10] Ditzian, Z. and Totik, V., Moduli of Smoothness, Springer-Verlag, New York, 1987

[11] Erkus, E., Duman, O. and Srivastava, H. M., Statistical approximation of certain positive linear operators constructed by means of the Chan Chyan Srivastava polynomials, Appl. Math. Comput., 182 (2006), 213-222

[12] Gadjiev, A. D., The convergence problem for a sequence of positive linear operators on bounded sets and theorems analogous to that of P. P. Korovkin, Dokl. Akad. Nauk SSSR, 218 (1974), No. 5, Transl. in Soviet Math. Dokl., 15 (1974). No. 5, 1433-1436

Received: 26.04.2017; In revised form: 15.01.2018; Accepted: 22.01.2018

2010 Mathematics Subject Classification. 41A10, 41A25, 41A36.

Key words and phrases. Szász operators, modulus of continuity, rate of convergence, Weighted space, Sheffer polynomials.

Corresponding author: M. Mursaleen; mursaleenm@gmail.com 
[13] Gadjiev, A. D., On P. P. Korovkin type theorems, Mat. Zametki, 20 (1976), 781-786; Transl. in Math. Notes, (1978), No. (5-6), 995-998

[14] Gavrea, I. and Rasa, I., Remarks on some quantitative Korovkin-type results, Rev. Anal. Numér. Théor. Approx., 22 (1993), No. 2, 173-176

[15] Ismail, M. E. H., On a generalization of Szász operators, Mathematica (Cluj), 39 (1974) 259-267

[16] İspir, N. , On modified Baskakov operators on weighted spaces, Turkish J. Math., 25 (2001), No. 3, 355-365

[17] Jakimovski, A. and Leviatan, D., Generalized Szász operators for the approximation in the infinite interval, Mathematica (Cluj), 11 (1969), 97-103

[18] Kadak, U., Braha, N. L. and Srivastava, H. M., Statistical weighted B-summability and its applications to approximation theorems, Appl. Math. Comput., 302 (2017), 80-96

[19] Mazhar, S. M. and Totik, V., Approximation by modified Szász operators, Acta Sci. Math., 49 (1985), 257-269

[20] Mursaleen, M. and Ansari, K. J., Approximation by generalized Szász operators involving Sheffer polynomials,(2015) Dec 25, arXiv preprint arXiv:1601.00675

[21] Mursaleen, M. and Ansari, K. J., On Chlodowsky variant of Szász operators by Brenke type polynomials, Appl. Math. Comput., 271 (2015), 991-1003

[22] Mursaleen, M., Ansari, K. J. and Nasiruzzaman, M., Approximation by q-analogue of Jakimovski-Leviatan operators involving q-Appell polynomials, Iran. J. Sci. Technol. Trans. A Sci., 41 (2017), No. 4, 891-900

[23] Mursaleen, M., Khan, A., Srivastava, H. M. and Nisar, K. S., Operators constructed by means of q-Lagrange polynomials and A-statistical approximation, Appl. Math. Comput., 219 (2013), 6911-6918

[24] Özarslan, M. A., Duman, O. and Srivastava, H. M., Statistical approximation results for Kantorovich-type operators involving some special polynomials, Math. Comput. Model., 48 (2008), 388-401

[25] Srivastava, H. M., Mursaleen, M. and Khan, A., Generalized equi-statistical convergence of positive linear operators and associated approximation theorems, Math. Comput. Model., 55 (2012), 2040-2051

[26] Srivastava, H. M., Mursaleen, M., Alotaibi, Abdullah M., Nasiruzzaman, Md. and Al-Abied, A. A. H., Some approximation results involving the q-Szász-Kantorovich type operators via Dunkl's generalization, Math. Methods Appl. Sci., 40 (2017), 5437-5452

[27] Sucu, S. and Büyükyazıc1, İ., Integral Operators Containing Sheffer Polynomials, Bull. Math. Anal. Appl., Vol. 4 (2012), No. 4, 56-66

[28] Szász, O., Generalization of S. Bernstein's polynomials to the infinite interval, J. Research Nat. Bur. Standards, 45 (1950), 239-245

[29] Zhuk, V. V., Functions of the Lip1 class and S. N. Bernstein's polynomials, Vestnik Leningrad. Univ. Mat. Mekh. Astronom., 1 (1989), 25-30 (Russian)

\author{
1,2 Aligarh Muslim University \\ DEPARTMENT OF MATHEMATICS \\ 202002, ALIGARH, INDIA \\ E-mail address: mursaleenmegmail.com \\ E-mail address: rahmanshagufta14@gmail.com \\ 3 King KHALID UNIVERSITY \\ Department of MATHEMatics, College of Science \\ 61413, ABHA, SAUDI ARABIA \\ E-mail address: ansari.jkhursheed@gmail.com
}

